\title{
IR thermographic camera as useful and smart tool to analyse defects in organic solar cells
}

\author{
W. Przybył, K.A. Bogdanowicz, ${ }^{*}$ B. Jewloszewicz, A. Dylong, K. Dysz, A. Iwan, ${ }^{*}$ A. Januszko \\ Military Institute of Engineering Technology, Obornicka 136 Str., 50-961 Wroclaw, Poland
}

Received February 06, 2020; accepted April 06, 2020; published June 30, 2020

\begin{abstract}
The main goal of this paper was to show that organic layers prepared for organic solar cells construction can be partially characterized by an IR thermographic camera to detect dysfunctionalities of the active layer. Moreover, we used an IR thermographic camera to check the thermal and electrical behaviour of created simple solar cells to reduce time and cost in global production of solar cells. As model system organic compounds such as PTB7 polymer and small molecule $\mathrm{PC}_{71} \mathrm{BM}$, there were used commercial components and newly synthesized imine PV-BLJ-SC11 to construct simple devices.
\end{abstract}

In the $21^{\text {st }}$ century, among various hot topics, solar energy and global sustainable growth together with ecological aspects are on the top science and industry list [1]. In the Military Institute of Engineering Technology (Wroclaw, Poland) we investigated in detail solar cells which are based on inorganic (silicon) and organic compounds as stiff and flexible substrates. We investigated devices based on dye (Dye Sensitized Solar Cells), organic compounds (organic and polymer solar cells) and perovskite (perovskite solar cells) [2]. One of the main problems in all types of solar cells is the existence of different mechanical and structural defects resulting in the decrease of photovoltaic parameters, mainly the fill factor (FF). It is well known that to analyse defects in solar cells, various techniques are used. However, IR thermal imaging can be seen as a fast and simple method for locating defects [3-6].

In our work, thermal behaviour was observed a using thermographic camera (VIGOcam V50, VIGO System S.A, Poland) while applying bias voltage between 0 and $10 \mathrm{~V}$ and using a multichannel potentiostat-galvanostat (PGStat Autolab (PGStat Autolab M101, Metrohm, Nederland) connected to a computer. In the experiment, voltage was applied in a range from $0 \mathrm{~V}$ to $10 \mathrm{~V}$ with a $0.5 \mathrm{~V}$ step increment; each voltage value was maintained for three minutes. The current response was recorded during all these three-minute-periods and in the last 10 seconds the IR image was collected (Fig. 1). The work of both camera and power source was controlled via computer software.

For the experiment, the active layers from the solution in dichloroethane with a total concentration of $15 \mathrm{mg} / \mathrm{mL}$ were prepared by a spin-coating method at $5000 \mathrm{rpm}$ for $20 \mathrm{~s}$ producing a layer of about 40-nm-thick. The experimental procedures were described in our previous work [7]. The chemical structure of synthesized imine is presented in Fig. 2. The new symmetrical imine, containing a triphenylamine core and an aromatic conjugated structure, possessed typical structural components similar to already known molecules used in organic solar cells [8]. For this reason, we used this compound as an active layer component to construct simple devices to test its thermal behaviour under applied voltage.

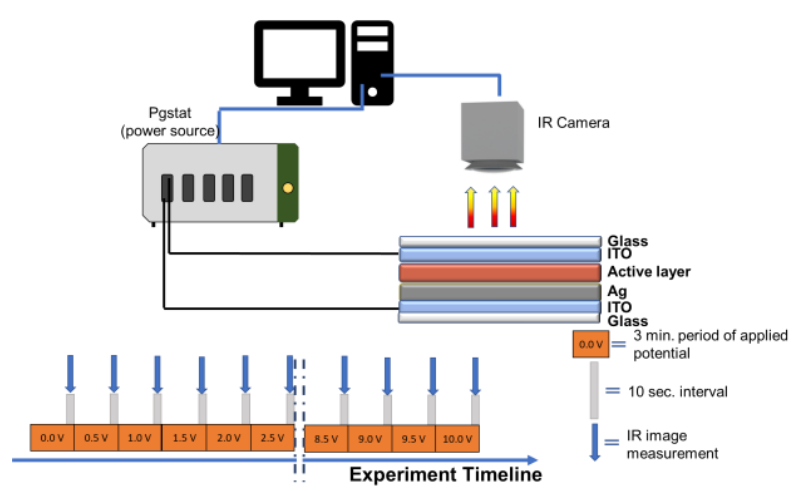

Fig. 1. Graphical representation of the experimental setup and design.

Synthesis of $\left[4,4^{\prime}-(\right.$ phenylimino)bisbenzaldehydene $]-d i-\{-$ 4-[4-(4-fluorophenyl)-1,3-thiazol-2-yl]imine \} PV-BLJ-11 has been performed as follows [9]: 4,4'diformyltriphenylamine $\quad(2 \mathrm{mmol}), \quad 4-[4-(4-$ fluorophenyl)1,3-thiazol-2-yl]aniline $(5 \mathrm{mmol})$ and $\mathrm{p}$ toluenesulfonic acid ( $10 \%$ by molar fraction) were mixed at $150^{\circ} \mathrm{C}$ for 48 hours. Finally, the solid was dried for 24 hours at $60^{\circ} \mathrm{C}$. The chemical structure was established by NMR and FT-IR techniques. The imine bond was observed at $8.48 \mathrm{ppm}$ in ${ }^{1} \mathrm{H}$ NMR spectra.

\footnotetext{
*E-mail: bogdanowicz@witi.wroc.pl; iwan@witi.wroc.pl
} 


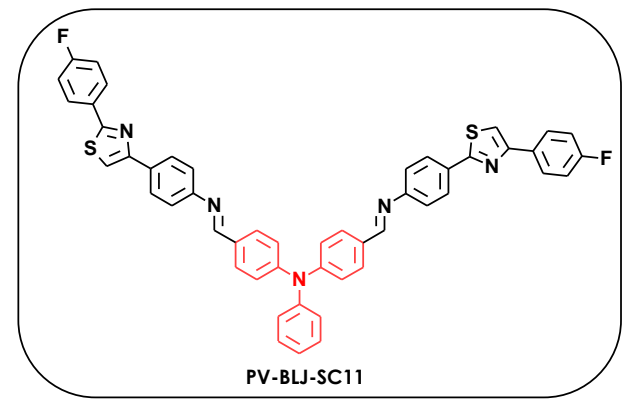

Fig. 2. Chemical structure of PV-BLJ-SC11.

In this study, a thermal imaging technique was employed for a simple device to observe its overall behaviour while an external potential was applied. This technique is used for detecting local defects in layers. The device contained PV-BLJ-SC11 and its mixtures with PTB7 or $\mathrm{PC}_{71} \mathrm{BM}$ compounds in a weight ratio 1:1. As reference, the device with PTB7 was constructed and analysed. For this experiment, the active layers were prepared using a spincoating technique over a glass support covered with an indium-tin oxide (ITO) conductive layer. The architecture of the devices can be described as follows:

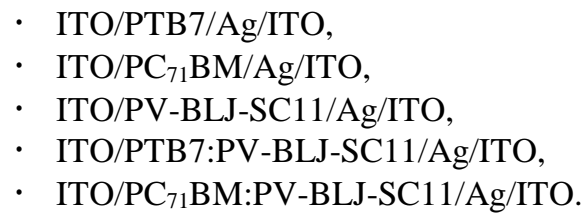

Figure 3 presents the constructed devices containing PVBLJ-SC11 and mixtures with PTB7 and $\mathrm{PC}_{71} \mathrm{BM}$. Generally, all devices composed of four layers containing one or two components demonstrated a very similar thermal topographic response to the applied voltage: as it can be seen on the exemplary images, while increasing the voltage, one main heating centre located in the proximity to one of the metallic contacts can be observed. This kind of behaviour was also observed in our previous works [7, $10]$.

This can be explained by the concentration of the current flow close to the metallic clamps and imperfect interface between the metal and ITO. During the experiment, the maximum thermal response ranged between $40^{\circ} \mathrm{C}$ and $130^{\circ} \mathrm{C}$ (see Fig. 4). The device containing only PTB7 demonstrated the highest observed temperature, while $\mathrm{PC}_{71} \mathrm{BM}$ showed the lowest values, up to $53^{\circ} \mathrm{C}$. The thermal response of imine and its mixtures with PTB7 or $\mathrm{PC}_{71} \mathrm{BM}$ was in between the above-mentioned pure compounds. The thermal response to the current flow for

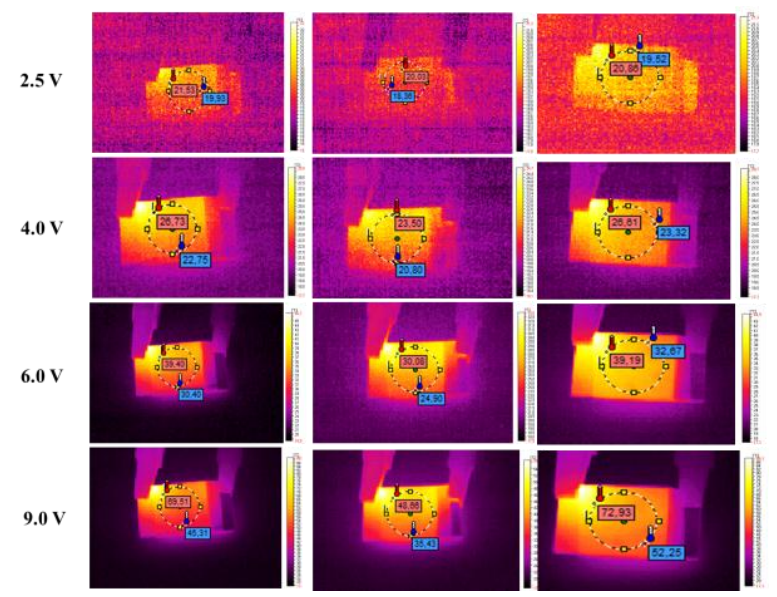

Fig. 3. IR images obtained for devices architecture: ITO/PV-BLJSC11/Ag/ITO (left side), ITO/ PTB7:PV-BLJ-SC11/Ag/ITO (middle side) and ITO/ $\mathrm{PC}_{71} \mathrm{BM}: \mathrm{PV}-\mathrm{BLJ}-\mathrm{SC} 11 / \mathrm{Ag} / \mathrm{ITO}$ (right side) at $2.5 \mathrm{~V}$, $4.0 \mathrm{~V}, 6.0 \mathrm{~V}$ and $9.0 \mathrm{~V}$.

pure imine gave temperature values higher than those obtained for mixtures with PTB7 and $\mathrm{PC}_{71} \mathrm{BM}$.The addition of PTB7 to the imine decreased the thermal response compared to $\mathrm{PV}-\mathrm{BLJ}-\mathrm{SC} 11$, giving the lowerest thermal response, approx. $48^{\circ} \mathrm{C}$, after which the temperature slowly decreased, suggesting a damaged active layer. Meanwhile, the addition of $\mathrm{PC}_{71} \mathrm{BM}$ did not affect the thermal behaviour significantly.
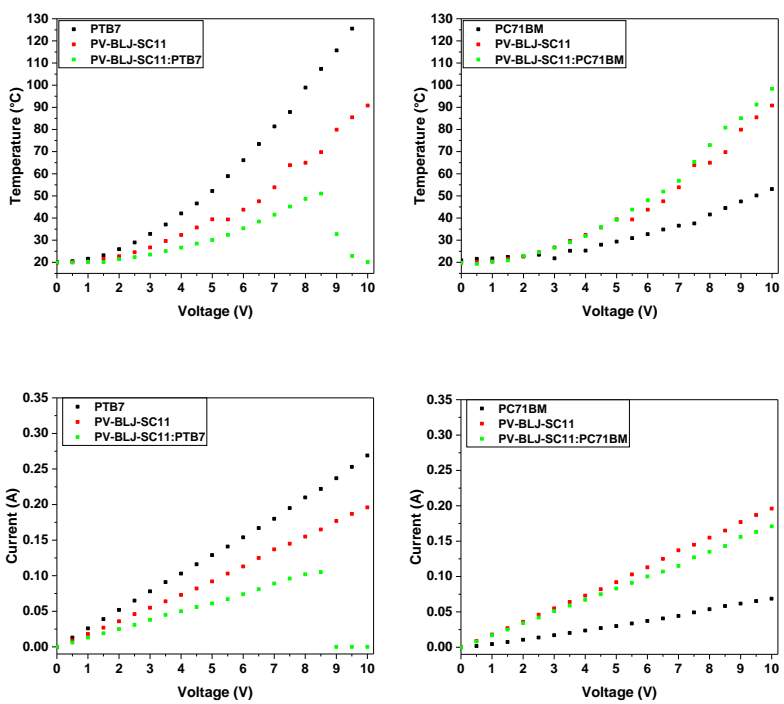

Fig. 4. The correlation of temperature or current versus applied potential for constructed devices containing PTB7 or PC71BM, PV-BLJ-SC11 and their mixtures (mixtures with PTB7- left and with $\mathrm{PC}_{71} \mathrm{BM}$ - right)

Regarding the electrical conductivity, all samples acted as electrical conductors and displayed a linear increment of current upon increasing applied potential. The resistance of $1 \mathrm{~cm}^{2}$ ranged from $20.6 \Omega$ to $84.8 \Omega$ : for PTB7 and $\mathrm{PC}_{71} \mathrm{BM}$, respectively, which is consistent with the 
thermal behaviour of a sample configuration presented in Fig 1. The resistance of PV-BLJ-SC11 (28.2 $\Omega$ ) was lower than for the layer containing a mixture of imine with PTB7 or $\mathrm{PC}_{71} \mathrm{BM}$ of about 4 and $15.2 \Omega$, respectively. Moreover, for the architecture ITO/PTB7:PV-BLJSC11/Ag/ITO, a drastic drop of current to zero was observed for voltages above $8.5 \mathrm{~V}$, aligning well with a drop of temperature, and also providing clear evidence of active layer destruction.

The in-depth analysis of thermal photographs focussed on defects visualization revealed the presence of some isotherms (Fig. 4, top, marked with dotted lines) in all constructed devices. In the case of devices with a singlecompound active layer (PV-BLJ-SC11, PTB7 or $\left.\mathrm{PC}_{71} \mathrm{BM}\right)$ only one major heating zone located around the working electrode (positively charged) was easily distinguishable. Apart from this, a gradual temperature decrease was observed with one noticeable horizontal boundary (Fig. 5 top, marked with dotted lines) across the middle of the device. For the device containing mixture PTB7:PV-BLJ-SC11 (Fig. 5, middle) it presented similar characteristics, expanded counter to the electrode. The device containing mixture $\mathrm{PC}_{71} \mathrm{BM}$ : PV-BLJ-SC11 (Fig. 5, bottom) displayed more defects than other samples. Apart from two isotherms: one centred at the working electrode and the other one at the horizontal boundary approximately in the middle of the sample (white dotted lines), two cooler spots were observed and marked with a blue arrow. These spots might suggest an imperfection of the spin-coated layer, where agglomerates of $\mathrm{PC}_{71} \mathrm{BM}$ could be formed, judging by a poorer thermal response of this compound.

To summarize, in our study we presented a new symmetrical imine containing a triphenylamine core, in perspective, to be used as an active material in organic solar cells, testing its thermal behaviour in three configurations: for imine alone and for a mixture with PTB7 or $\mathrm{PC}_{71} \mathrm{BM}$. The thermal imaging for devices built of two-component layers showed a wider area where the temperature was higher. It might be related to the fact how homogenous the mixing is of imine and second compound within the layer: lower molecule packing in the layer increases the free space volume, hence a decreased current flow. The coupling with a simultaneous current registration gave full information about the condition of the active layer, which in the case of PTB7:PV-BLJ-SC11 mixture demonstrated full degradation of the layer after reaching $8.5 \mathrm{~V}$. The thermal imaging for devices built of two-component layers showed a wider area where the the temperature was higher. It might be related to how homogenous the mixing is of imine and the second compound within the layer.

This can be explained by the presence of fluorophenyl moiety in imine that probably reacts at high potentials with the aromatic structure of PTB7 and PC71BM, causing a chain reaction that deactivates the aromatic

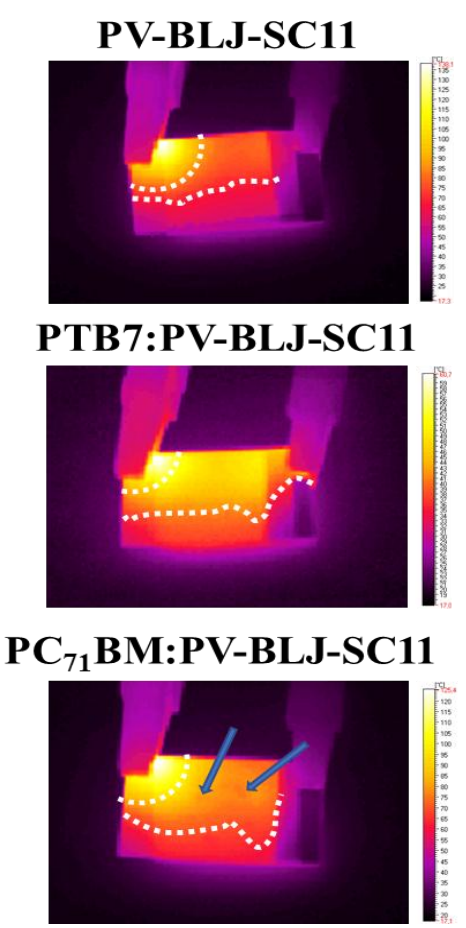

conductive structure.

Fig. 5. IR images obtained for devices at the highest voltage with marked isotherms (white doted lines) and spots (blue arrow).

Authors are grateful for the financial support from the Polish National Centre of Research and Development (TECHMATSTRATEG1/347431/14/NCBR/2018).

\section{References}

[1] K.D.G.I. Jayawardena, L.J. Rozanski, C. A. Mills, M. J. Beliatis, N.A. Nismy, S.R.P. Silva, Nanoscale 5, 8411 (2013).

[2] Y. Lin, X. Zhan, Accounts of Chem. Research 49, 175 (2016).

[3] R. Steim, S.A. Choulis, P. Schilinsky, U. Lemmer, C.J. Brabec, Appl. Phys. Lett. 94, 043304 (2009).

[4] J. Hepp, F. Machui, H.J. Egelhaaf, C.J. Brabec, A. Vetter, Energy Science Eng. 4, 363 (2016).

[5] H. Hoppe, J. Bachmann, B. Muhsin, K.H. Drüe, I. Riedel, G. Gobsch, C. Buerhop-Lutz, C.J. Brabec, V. Dyakonov, J. Appl. Phys. 107, 014505 (2010).

[6] J. Bachmann, C. Buerhop-Lutz, C. Deibel, I. Riedel, H. Hoppe, C.J. Brabec, V. Dyakonov, Solar Energy Mat. Solar Cells 94, 642 (2010).

[7] A. Różycka, K.A. Bogdanowicz, N. Górska, J. Rysz, M. Marzec, A. Iwan, R. Pich, A. Januszko, Materials 12, 1097 (2019).

[8] M.L. Petrus, R.K. M. Bouwer, U. Lafont, S. Athanasopoulos, N.C. Greenham, T.J. Dingemans, J. Materials Chemi. A 2, 9474 (2014).

[9] K.A. Bogdanowicz, A. Iwan, March 11, 2019: patent application P.429044.

[10] K.P. Korona, T. Korona, D. Rutkowska-Zbik, S. GrankowskaCiechanowicz, A. Iwan, M. Kamińska, J. Phys. Chem. of Solids 86 , 186 (2015). 